sicians to the local and state boards of health is still far from what it should be. Although there has been undoubted improvement in this regard, statistics prove that there still exists great laxity in obedience to the law requiring physicians to report all cases. Nothing is more demoralizing to a community than disregard and contempt of laws which are made for the protection of the health of all. Constant watch is, therefore, necessary in such matters to see that laws are enforced. There has been a very marked improvement in recent years, since the anti-spitting laws were made. This is especially notable in our railroad and trolley cars, except in the smoking compartments, which are often in a disgraceful condition. Spitting upon the platforms and sidewalks, however, is still rife in most communities and demands a more rigid enforcement of law. A few arrests for misdemeanors have had in times past a wonderfully beneficial effect, which, however, gradually lessens as those in authority relax in their vigilance. Our tuberculosis societies and members of our League still have much missionary work to do in all these matters.

We have every reason for encouragement in our work. Dogged persistence is the only way to accomplish the desired end. We are having constant proofs of the decline in the death rate from tuberculosis, but a complacent optimism on the subject is not going to bring success. Only by united effort such as can be accomplished by the societies which form our League, can we hope to get control of the disease.

In this connection, I am glad to call special attention to the interesting experiment now being made by the Metropolitan Life Insurance Company of New York, which has established a "Community Health Station" in Framingham, Mass. That a Massachusetts town should have been selected for this is most gratifying, and there is promise of deeply interesting results which may be much more far-reaching throughout our country than we now dream. We are fortunate in having with us today Dr. Donald Armstrong, who has this experiment in charge. This work will offer an excellent opportunity for study to the members of our League so far as it touches the question of tuberculosis.

How much has been accomplished during the year in regard to the after-care of consumptive patients who have been discharged from sanatoria,-a subject of paramount importance,we shall learn in a paper to be given today by Miss Billings.

It cannot be reiterated too often, that however successful we may be in establishing sanatoria, hospitals, and dispensaries or whatever for the cure and treatment of tuberculous patients, we must constantly keep in mind the still greater importance of preventive measures. We know that improper housing, poor accommodations in factories, and impure milk are prolific causes for the production of the disease. Persistent work in our ever-increasing attempts to remedy these evils will, we have every reason to hope, result in a still greater decrease in the mortality of this disease in the coming years.

\section{Tuberculosis in Dairy Cattle.}

By Curtis M. Hilliakd, Boston,

Professor of Biology and Public Health, Simmons College.

Tuberculosis in cattle has been more or less neglected by anti-tuberculosis societies because of its relatively low incidence in humans compared with the human type of infection. On the other hand, the fact that the occurrence of bovine tuberculosis in man is absolutely preventable, while the human variety is, at best, reducible only, would seem to make it imperative that the cattle disease should receive prompt and vigorous attention by all agencies and societies that aim at this scourge. The diseases that are generally transmitted from person to person, as contrasted with those that depend primarily upon some intermediate host or inanimate vehicle, are more difficult to control, for we can take any measures we choose in combating the microbes in the latter sources, while infected human beings must be treated with due regard to personal liberties, and they are willful agents, who must to some extent mingle with other persons. So cows, and food products derived from these animals, are amenable to any legislation we may choose to enact and enforce, or any specific treatment any owner may choose to practice. The human type of bacillus-almost ubiquitous in man-is kept within bounds chiefly in proportion to the degree of intelligent care which the patient uses in regard to the oral discharges, for he is only slightly responsible to legislation and enforced treatment.

Tuberculosis in cattle was recognized by Koch in 1882 in his early work on tuberculosis. $\mathrm{He}$ believed at that time that the microbic agent in the two hosts was identical, and this view was generally accepted until 1896, when Theobald Smith described certain striking differences, which have since that time been amplified. The professional world was startled in 1901 at the announcement by Koch that human and bovine tuberculosis were distinct entities, and that there was practically no danger to man from the existence of the disease in cattle. This stimulated a tremendous amount of work in many countries, which has led to the unanimous conclusion that bovine tuberculosis not only may be transmitted, but actually is frequently the cause of the disease in man.

The bovine bacillus resembles the human type in general, but tends to be a somewhat stouter, more solid staining organism. It is more virulent for animals ordinarily used in the laboratory, particularly the rabbit, and upon culture 
media containing glycerine the fermentation curve is characteristic.

In nature, the bacillus is found to live an exclusively parasitic existence. It is found to occur chiefly in the bodies of dairy cattle, but may also infect beef cattle, hogs raised in dairy districts, and rarely other animals, and finally is found in man. It is difficult to make any general statement regarding its prevalence in cattle. Less than $1 \%$ of beef cattle are tuberculous. In dairy herds, the disease seems to ravage the Eastern states more than the Western in this country. In New York, from 1910-1912, of 39,330 cattle examined by the tuberculin test, 7171 , or $19 \%$, reacted. In Vermont, during the last four years, out of approximately 29,000 tests, between 10 and $11 \%$ have reacted. The state commissioner on domestic animals in Connecticut states in the 1916 report "that $30 \%$ of our cattle are infected with this dreaded disease seems probable from those found in the herds, the owners of which have taken advantage of the tuberculin test." The Massachusetts commissioner states $12 \%$ as an approximate figure for this state. Of 35,000 cattle examined in England, about one-fourth proved tuberculous. Further citation of figures would be tedious. To be extremely conservative, let us say that $10 \%$ of all dairy cattle furnishing milk to our large cities for infants, children and adults alike, are infected with a disease which is transmissible to man.

To be transmissible, the bacillus must be able to pass from the infected animal to man, and we must next inquire as to the possibilities for this to occur.

The muscles of the animal are rarely diseased. The federal government and most of the states are very particular about passing meat for human food which comes from diseased animals. Meat is usually heated before consumption and, even if infected, would be rendered safe by this practice. Fortunately, it is now possible to conserve valuable food from animals not "passed" for first-class meat, by sterilizing it in cans and labelling it "second class" meat.

Milk and milk products are the chief go-betweens for the bacillus passing from cows to man. The germ rarely infects the milk glands, but when it does a most grave menace exists, for there may be almost as many tubercle bacilli in the milk as there are in sputum in active human cases, and it will dangerously infect the milk of a large number of cows, when mixed. The disease usually exists as a lung infection in cattle. The nose and throat discharges are infectious and serve as a fruitful source of infection amongst cattle themselves, but no special opportunity is afforded for the infection of milk directly from this source. Indirectly, however, the germs from this origin find their way into milk. They are "raised" by coughing, swallowed, and pass through the whole length of the alimentary tract in a virulent condition. In manure they will survive for some time, probably for weeks. Briscoe found artificially inoculated cow manure, exposed in a field for two months, still to retain virulent bovine bacilli.

Almost all milk contains some cow manure, and so it might be anticipated that bovine tubercle bacilli will sometimes be found in milk The following table is taken from Rosenau "The Milk Question."

TUBERCLE BACILII IN MARKET MILK.

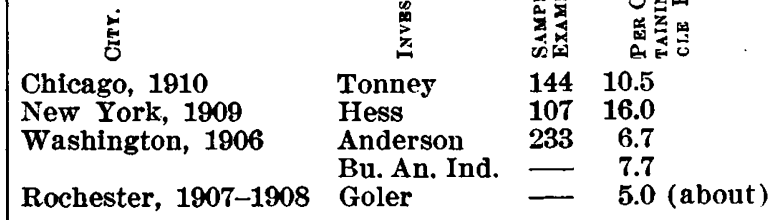

Probably between 7 and $8 \%$ of milk in our large cities contains tubercle bacilli. Ice cream, butter and cheese may also contain tubercle bacilli of animal origin. Cream, separated from milk, either naturally or by centrifugal force, carries bacteria with it, so that it contains several times as many organisms as does the skimmed milk. Examinations of these prod. ucts, particularly butter, reveal the tubercle bacillus to be present altogether too commonly for comfort. It might be thought that the salt in butter and its storage in the cold would render the microbes harmless in a short time. In general, storage in the cold has a tendency to eliminate pathogenic bacteria, but in this case Mohler of the United States Bureau of Animal Industry has demonstrated the tubercle bacilli to remain virulent for 160 days in salted butter and for 261 days in cheese. Other investigators have not always proved such endurance, but most agree that the bacillus will survive for many weeks, - time ample for transmission to man. Furthermore, the bacillus enters through the mucosa of the intestine most conveniently with a fatty diet, so that these products are of great importance in relation to the problem.

The prevention of bovine tuberculosis in man is conveniently discussed under two separate headings: (1) The elimination of tuberculous cattle. (2) The pasteurization of milk.

Although tuberculosis is the cause of very serious economic loss to owners of dairy cattle, it is hard to make them appreciate this on account of the slow, subtle inroads of the disease. Contagious abortion, anthrax or foot-and-mouth disease stir the imagination and they will, for definite losses occur rapidly. Tuberculosis may be unsuspected in the dangerous animal, so far as physical conditions are concerned, and remains for years, perhaps, to infect other animals and to seed the milk. A careful routine physical examination by the competent veterinary will go a long way to keep a herd free from this disease, but a much more dependable diagnosis is 
known in the tuberculin test. The test is harmless, and of its kind is one of the most delicate tests known. In fact, it is so precise that this itself is almost a disadvantage, for it picks out animals with latent lesions, which might be milked with perfect safety for the time being, at least. It is better to err on the safe side, however, as such animals are potential active cases.

Time does not permit a consideration of the method and mechanism of the tuberculin test. Suffice it to say that the test has the confidence of most o fthe veterinary profession to detect tuberculosis in cattle, and to be absolutely harmless. That its use should not be promiscuous and should be performed only by those trained in the method and interpretation of results, goes without saying.

Given the information regarding the occurrence of tuberculosis, the badly diseased may be destroyed, while the slightly diseased may bo isolated. The former, in most states, are paid for in part, at least, if the slaughtering and examination are supervised by a proper authority of the state. The reactors not seriously diseased are separated from the remainder of the herd and are used for breeding purposes, the calves being immediately removed when dropped. The milk may be heated and fed to calves and other stock. It is of fundamental importance to protect calves from infection and to avoid the introduction of infected cattle by purchases. What may be done by intelligent precaution is suggested by comparing the number of condemned animals tested upon application, and those tested for interstate shipment in the state of Vermont. The latter represent dealers who, in general, take precautions to keep their stock as free as possible from tuberculosis; while the former are the average, more in different owners.

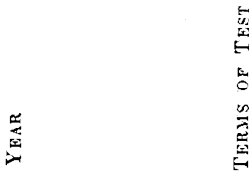

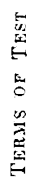
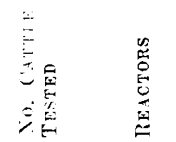

1912-1914 On application of

owners $\ldots \ldots \ldots \ldots \ldots \quad 16,985 \quad 1,601 \quad 9.39$ Under terms for shipment out of state

1914-1916 On application of owners $\ldots \ldots \ldots \ldots$ Inder terms for shipment out of state

601

1,681

$59 \quad 3.51$

$11,961 \quad 1,390 \quad 11.62$

$9,702 \quad 360 \quad 3.7 \%$

This table shows what may be done, and should suggest the wisdom of routine testing for all farmers and breeders, from the economical standpoint alone.

The matter of introducing tuberculous-free stock only into herds which are being tested makes a heavy demand for guaranteed animals, and some official system of classification of tuberculous-free herds by proper authorities should be of considerable assistance, encouragement, and remuneration to those farmers who are striving toward the goal. Officially recog- nized cattle could be sold and delivered in other states without the annoyance, delay and expense of performing the tuberculin test immediately prior to shipment. Such a plan, we understand, has operated successfully in the state of Illinois through the Board of Live Stock Sanitary Commissioners, the herds being divided into three classes according to the per cent. of reactors found at the last preceding tuberculin test.

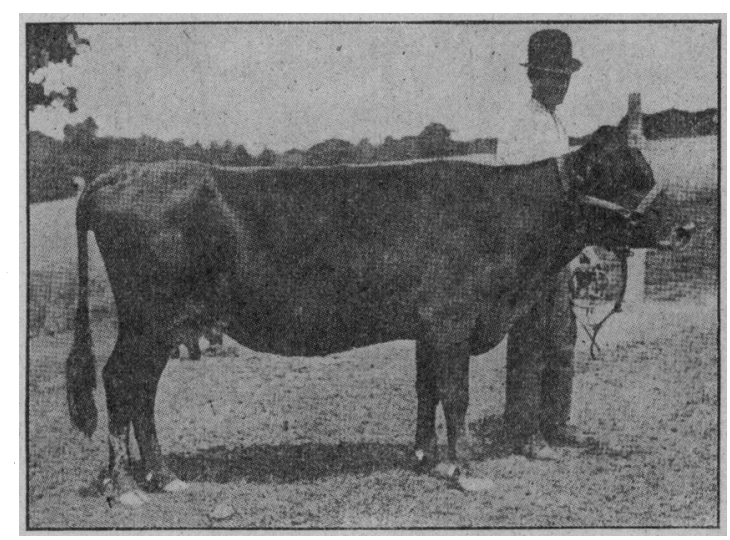

Fig. 1.- A dangerously tuberculous cow. In appearance the subject of this picture is a well-kept family cow. She is dangerously tuberculous, because she expels tubercle bacilli from her body per rectum with her feces.

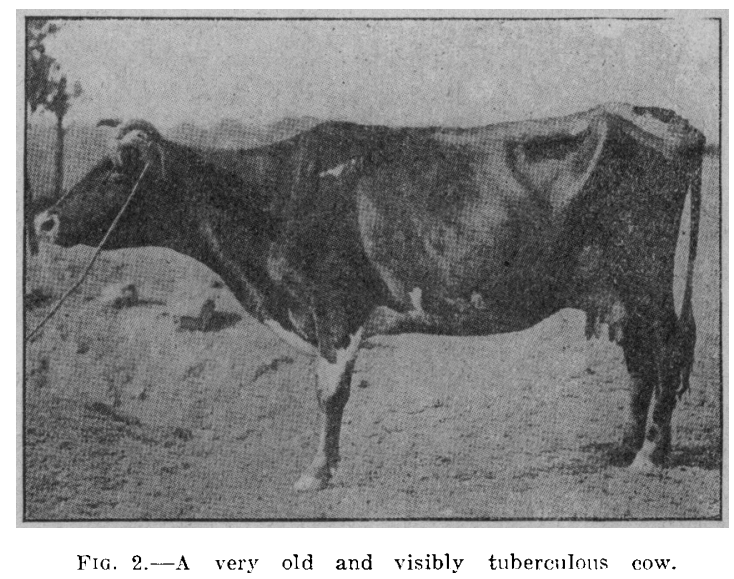

It will be a long, long time before tuberculosis is stamped out of dairy cattle, and if we must depend upon this effort alone for protection of milk and milk products from transmitting the disease, the statement that I made regarding its absolute preventability would look doubtful indeed.

With the disease existent in cattle and with market milk commonly infected, we must attack the problem from another standpoint, and that is to destroy the microbe potentially in the milk. The production of clean milk with all that it involves as to structure of barns, cleaning of stables and animals, sterilizing of receptacles and the other manifold problems, is most important and should be encouraged and enforced. From the standpoint of the prevention of tuber. 


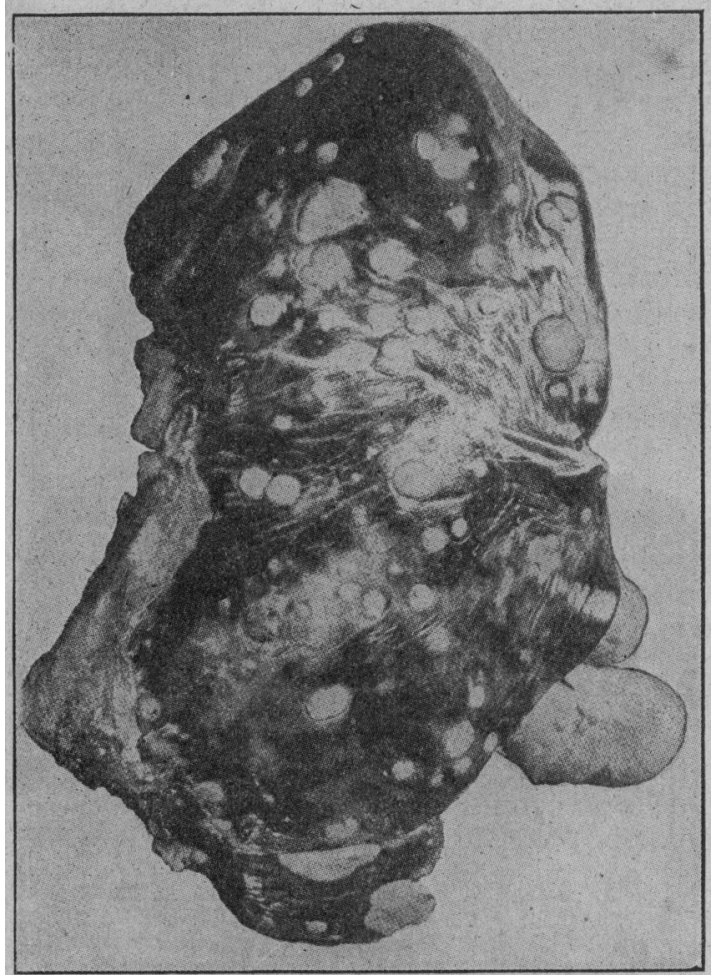

Fic. 3.-Liver of cow, showing many lesions on surface, aml gallbladder at lower right side of cut.

culosis, however, all these matters dwindle to relatively small dimensions when contrasted with pasteurization. It is difficult to understand the prejudice held against the practice of

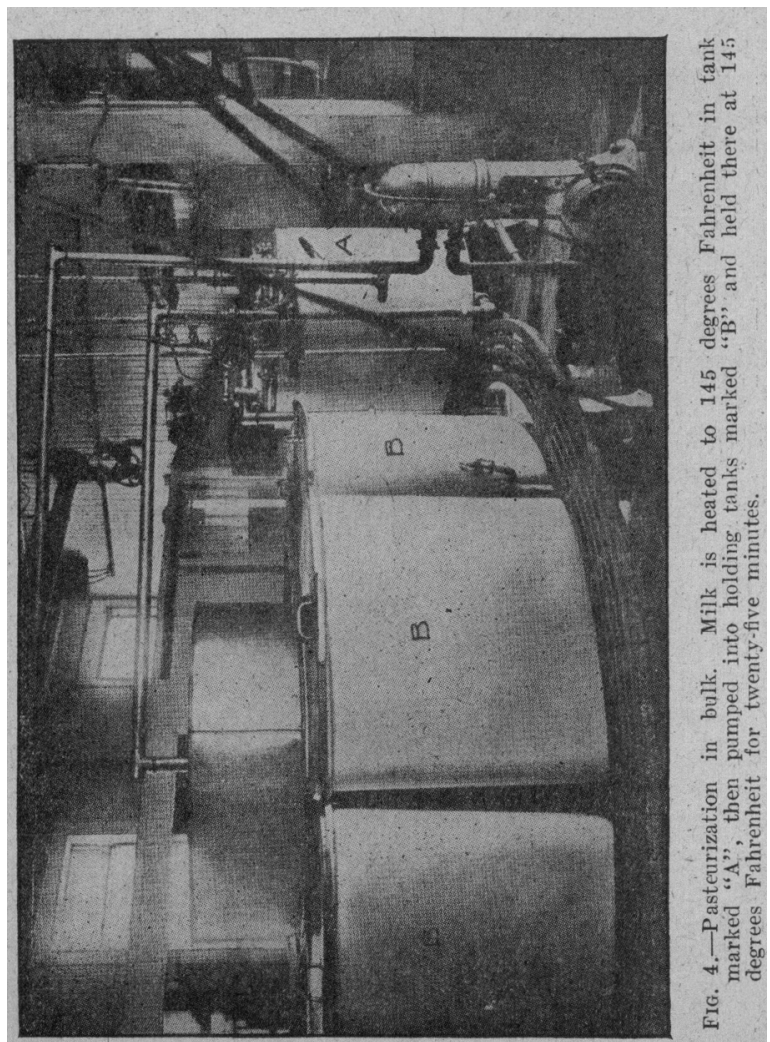

heating milk when it is the common procedure with almost all other animal food products. I am of the opinion that the occurrence of bovine tuberculosis in man is wholly preventable by the performance of this simple, common-sense practice under authoritative supervision. We have wrangled for years over the pros and cons of pasteurization, but all the conscientious objections raised in the early days have, one by one, been overthrown by scientific laboratory investigation and by practical results, until now argument and authoritative opinion are over-

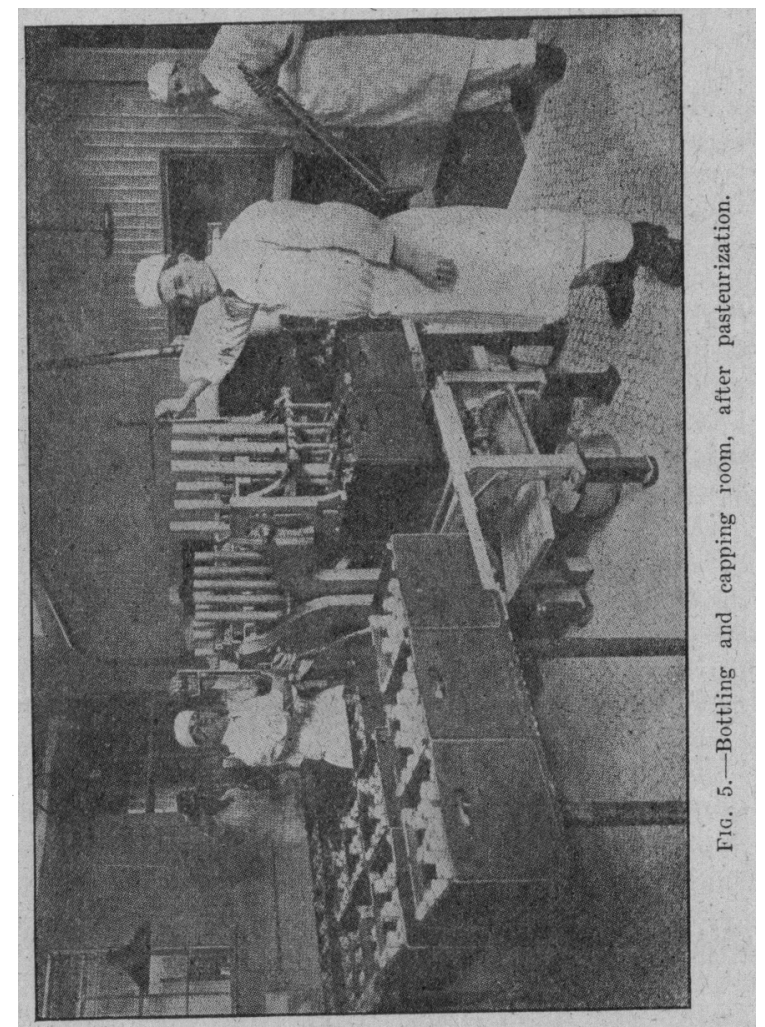

whelmingly in favor of heating milk to the relatively low temperature required to kill all pathogenic microbes. I know of no easier, cheaper, more certain way of avoiding any disease than by practising pasteurization of milk, and I belicve it one of the most important functions of anti-tuberculosis leag'ues to do all in their power to bring about the day of compulsory pasteurization of all milk, except certified (and the day will come when most of that is heated also), which comes to our cities.

\section{The Danger to Children From Tuberculosis} in Cattle.

By limemard M. Smxth, M.D., Boston.

Mr. Presinent: What I want to say is a very brief application of the facts which Professor Hilliard has given you. Bovine tuberculosis as it affects children represents, of course, only a small part of the disease in children, but it does 